\title{
Desempenho reprodutivo de ovelhas mestiças da raça Santa Inês em Brachiaria humidícula e efeito do sexo no ganho de peso de cordeiros
}

\author{
[Reproductive performance of crossbred ewes race Santa Ines in Brachiaria humidicula \\ and effect of sex on weight gain of lambs] \\ P.A. Oliveira ${ }^{1}$, L.G.A. Cirne ${ }^{2}$, D.C. Almeida ${ }^{3}$, G.J.C. Oliveira ${ }^{4}$, S.M.P.L. Jaeger ${ }^{4}$, E.S.O. Strada ${ }^{4}$, \\ A.R. Bagaldo ${ }^{4}$, R.L. Oliveira ${ }^{5}$

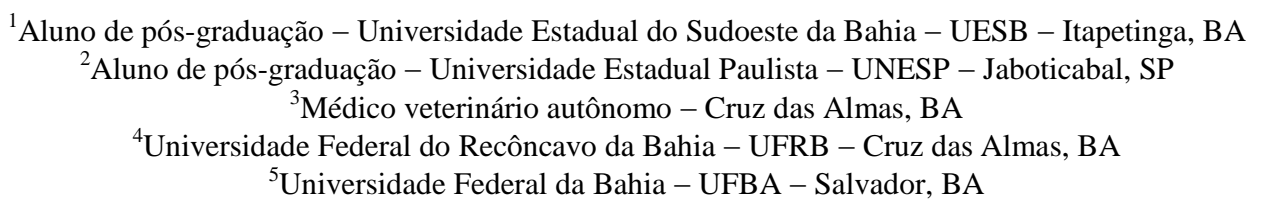

\section{RESUMO}

Objetivou-se avaliar o desempenho reprodutivo de ovelhas deslanadas em função do manejo alimentar das crias e idade de desmame, além de mensurar o efeito do sexo no ganho de peso de cordeiros. Sessenta e quatro ovelhas mestiças da raça Santa Inês foram distribuídas em delineamento inteiramente ao acaso, em esquema fatorial 4 × 2 × 2 - quatro idades de desmame (56, 70, 84 e 98 dias), sexo e manejo alimentar das crias, cada tratamento com quatro repetições. As ovelhas foram manejadas com a cria ao pé, em 14 piquetes de 1,5 ou 2,0 hectares, formados com pastagem de Brachiaria humidícola. As crias nascidas de partos simples, filhos de reprodutores Santa Inês puros de origem (PO). Após o desmame de todos os grupos, sessenta e quatro cordeiros (32 machos e 32 fêmeas) foram distribuídos ao acaso em baias individuais e confinados por 30 dias. A comparação dos parâmetros foi realizada pelo ajuste do modelo de regressão linear simples. Verificou-se vício de tempo longo do manejo alimentar das crias de $+3,7 \%(\mathrm{P}<0,05)$ para o intervalo entre partos e de $+1,4 \%(\mathrm{P}<0,05)$ para o período de serviço. Houve efeito linear crescente $(\mathrm{P}<0,05)$ da idade de desmame sobre o intervalo entre partos e período de serviço. Verificou-se vício de tempo longo do sexo das crias de $+2,0 \%(\mathrm{P}<0,05)$ para o intervalo entre partos e de $+0,8 \%(\mathrm{P}<0,05)$ para o período de serviço das ovelhas. Constatou-se vício de tempo longo do sexo de + $35,2 \%$ e $+36,9 \%(\mathrm{P}<0,05)$, respectivamente, para o ganho de peso diário de cordeiros do nascimento ao desmame e pós desmame em confinamento. A suplementação das crias em alimentador privativo e a antecipação da idade de desmame reduzem o intervalo entre partos e período de serviço de ovelhas deslanadas em pastagem de Brachiaria humidícula. O sexo da cria é fonte de variação na análise da eficiência reprodutiva de matrizes ovinas e no ganho de peso de cordeiros mestiços da raça Santa Inês do nascimento ao desmame e após o desmame.

Palavras-chave: ovelha, desenvolvimento corporal, eficiência reprodutiva, idade de desmame

\begin{abstract}
The purpose was to evaluate the reproductive performance of woolless ewes due to the feeding management of offsprings and weaning age in addition to measuring the effect of gender on weight gain of lambs. Sixty-four Santa Inês crossbred ewes were distributed in a completely randomized design in a factorial $4 \times 2 \times 2$-four weaning ages (56, 70, 84 and 98 days), sex and feeding management of the offspring, each treatment with four replications. The ewes were managed with the offsprings at the foot in 14 paddocks of 1,5 or 2,0 hectares, formed with Brachiaria humidícola. The offsprings were born by single birth, of Santa Inês pure of origin (PO). After the weaning of all groups, sixty-four lambs (32 males and 32 females) were randomly assigned in individual stalls and confined for 30 days. The comparison of
\end{abstract}

Recebido em 2 de fevereiro de 2013

Aceito em 19 de junho de 2013

E-mail: pazootecnista@gmail.com 
the parameters was carried out by the adjustment of the simple linear regression model. It was verified over time addiction of the offspring feed management of $+3,7 \%(P<0,05)$ for the calving intervals and of $+1,4 \%(P<0,05)$ for the service period. There was increasing linear effect $(P<0,05)$ of weaning age on calving intervals and service period. It was verified over time, addiction of the offspring sex of $+2,0 \%$ $(P<0,05)$ for the calving intervals and $+0,8 \%(P<0,05)$ for the ewes service period. It was observed over time addiction of sex of $+35,2 \%$ and $+36,9 \%(P<0,05)$, respectively, for the daily weight gain of lambs from birth to weaning and post-weaning in feedlot. The supplementation of the offspring in private feeder and the anticipation of the weaning age reduce the calving intervals and the service period of woolless ewes in Brachiaria humidicula pasture. The offspring sex is the source of variation in the analysis of reproductive efficiency of ewe's matrices and in the weight gain of Santa Inês crossbred lambs from birth to weaning, and after weaning.

Keywords: ewe, body development, reproductive efficiency weaning age

\section{INTRODUÇÃO}

A raça deslanada de ovinos Santa Inês é um grupo genético naturalizado no Nordeste brasileiro, proveniente de sucessivos cruzamentos entre animais da raça Bergamácia com ovinos da raça Crioula e Morada Nova (Landim et al., 2011). Por ter surgido em região de baixa latitude, apresentam estro durante todo o ano, ou seja, são poliéstricas não estacionais em condições tropicais, possibilitando três parições em dois anos.

A interação animal-ambiente deve ser considerada quando se busca maior eficiência na exploração pecuária, pois as diferentes respostas do animal à condição edafoclimática de cada região é determinante no sucesso da produção animal.

Reduzir o período de anestro, antecipando a estação reprodutiva, constitui-se em importante fator econômico a ser considerado na ovinocultura de corte (Sasa et al., 2011). A eficiência reprodutiva, estimada através da frequência de partos, pode ser maximizada nos animais de produção por meio da diminuição do intervalo entre parto e concepção.

A adoção de alimentador privativo, prática que consiste no fornecimento de rações às crias, diminui a intensidade de mamada e, com isso, minimiza a demanda energética da lactação. A poupança energética das ovelhas durante essa fase pode ser direcionada para novo ciclo reprodutivo do rebanho (Villas Boas et al., 2003).

Os ovinos da raça Santa Inês podem apresentar ganhos de até $0,210 \mathrm{~g} / \mathrm{dia}$ em confinamento
(Araújo Filho et al., 2010). A distinção do ganho de peso por sexo contribui para o planejamento do ganho de peso do rebanho.

Objetivou-se definir o desempenho reprodutivo de ovelhas deslanadas, em pastejo de Brachiaria humidícula, em manejo com cria ao pé por meio do intervalo entre partos e período de serviço em diferentes idades de desmame e manejo alimentar das crias, e avaliar o efeito do sexo no ganho de peso de cordeiros.

\section{MATERIAL E MÉTODOS}

O experimento foi realizado em propriedade rural localizada no município de Jandaíra, litoral norte do Estado da Bahia, situado a $11^{\circ} 33^{\prime} 45^{\prime \prime}$ de latitude sul e $37^{\circ} 48^{\prime} 45^{\prime \prime}$ de longitude oeste.

O clima da região varia de úmido e subúmido até seco, que, de acordo com a classificação climática de Wilhelm Köppen, é do tipo As ("A": clima tropical com temperatura média mensal superior a $18^{\circ}$, e "s": estação seca no período de sol mais alto e dias mais longos).

As unidades geomórficas da região são formadas pelos tabuleiros pré-litorâneos de topografia plana, caracterizados por apresentar baixa fertilidade natural (SEI, 2009). Constatouse no solo da propriedade rural $\mathrm{pH}$ de 5,38 e nível de fósforo de $0,8 \mathrm{ppm}$.

Foram utilizadas 64 ovelhas mestiças da raça Santa Inês de terceiro a quinto partos. As crias nasceram de partos simples (32 machos e 32 fêmeas), filhas de reprodutores Santa Inês, puros de origem (PO), e peso vivo médio ao nascimento de $3,85 \mathrm{~kg}$ (de 3,0 a 4,6kg). 
As ovelhas foram manejadas com a cria ao pé, em 14 piquetes de 1,5 ou 2,0 hectares, formados com pastagem de Brachiaria humidícula, com lotação animal média de cinco matrizes/ha, período de ocupação de 1,5 ou 2 dias (proporcional à área de cada piquete) e intervalo de pastejo de 24 dias.

Diariamente, às $17 \mathrm{~h}$, um grupo de cria era recolhido num galpão, onde tinham acesso ao alimentador privativo até às $7 \mathrm{~h}$ do dia seguinte, quando retornavam aos piquetes. $\mathrm{O}$ suplemento foi composto por $68 \%$ de milho moído, $29 \%$ de farelo de soja e $3 \%$ de sal mineral $(19,37 \%$ de $\mathrm{PB}$ e $75,57 \%$ de NDT), verificando-se consumo médio diário de $125 \mathrm{~g}$.

No manejo reprodutivo, utilizou-se a monta controlada. Após a identificação do cio, as ovelhas eram levadas ao macho para serem cobertas. O manejo profilático seguiu o manejo da propriedade, em que todos os animais foram tratados com medicamento à base de moxidectina a $1 \%$, na dosagem de $1 \mathrm{~mL} / 50 \mathrm{~kg}$ de PV. O tratamento com moxidectina era realizado em todo o rebanho quando o resultado do exame de O.P.G., monitorizado por amostragem no rebanho da fazenda, ultrapassava 500 ovos por grama de fezes.

As crias foram desmamadas com 56, 70, 84 e 90 dias de vida. Após o desmame, as ovelhas voltavam para os piquetes, onde ficavam até o parto seguinte, com água e sal mineral à vontade. Foram anotadas todas as datas de partos das ovelhas e, posteriormente, calculado o intervalo entre partos e o período de serviço de cada ovelha do experimento. O período de gestação foi padronizado em 150 dias para o cálculo do período de serviço.

Após o desmame de todos os grupos, os cordeiros foram confinados por 30 dias em baias individuais de piso cimentado, com área útil de $1,5 \mathrm{~m}^{2}$ e cama de areia, onde receberam feno de Cynodon spp. Cv Tifton 85 (92,45\% de MS, $9,73 \%$ de PB, $78,85 \%$ de FDN, 39,05\% de FDA e $1,81 \%$ de EE), água e sal mineral à vontade. A ração concentrada $(19,95 \%$ de $\mathrm{PB}$ e $75,46 \%$ de NDT), composta de $66,4 \%$ de milho em grão, $30,6 \%$ farelo de soja e $3,0 \%$ premix vitamínico mineral, foi fornecida na proporção de $2 \%$ do PV por dia, dividida em duas refeições diárias, às 8 e 18h. Os ajustes nas quantidades de alimento concentrado fornecidas a cada animal, durante o período do confinamento, foram feitos sempre após as pesagens semanais individuais de todos os animais. Os cordeiros constaram pesos vivos médios ao abate de $20,45 \mathrm{~kg}$.

Utilizou-se delineamento inteiramente ao acaso em esquema fatorial $4 \times 2 \times 2$, ou seja, quatro idades de desmame $(56,70,84$ e 98 dias de idade), sexo das crias e manejo alimentar das crias, com quatro repetições por tratamento, totalizando 64 animais. Após o desmame de todos os grupos, os 64 cordeiros (32 machos e 32 fêmeas) foram distribuídos ao acaso em baias individuais e confinados por 30 dias.

A comparação dos parâmetros, intervalo entre partos e período de serviço das ovelhas em função do manejo alimentar das crias, sexo das crias e o efeito do sexo no ganho de peso dos cordeiros, foi realizada pelo ajuste do modelo de regressão linear simples, de acordo com o seguinte modelo: $\mathrm{Yi}=\mathrm{b} 1 \mathrm{xi}+\mathrm{ei}$, em que $\mathrm{Yi}=$ intervalo entre partos, período de serviço de matrizes e ganho de peso do sexo dos cordeiros, b1 = coeficiente de inclinação da reta, $x i=$ efeito do manejo alimentar da cria, sexo da cria e efeito do sexo no ganho de peso, ei $=$ erro aleatório associado a cada observação. A estimativa do parâmetro b1 da equação de regressão foi testada sobre as seguintes hipóteses: $\mathrm{H} 0: \beta 0=0 ; \mathrm{Ha}: \beta 0 \neq 0 ; \mathrm{H} 0: \beta 1=1$; $\mathrm{Ha}: \beta 1 \neq 1$

Quando da não rejeição da hipótese de nulidade, os valores de intervalo entre partos, período de serviço de matrizes em função do manejo alimentar das crias, sexo das crias e o efeito do sexo no ganho de peso dos cordeiros são similares, enquanto, no caso da rejeição da hipótese de nulidade, verifica-se a presença do vício de tempo longo (VTL).

O vício de tempo longo é considerado como: VTL $(\%)=(\beta-1) \times 100$, em que, $\beta=$ coeficiente de inclinação linear dos parâmetros avaliados, assumindo-se intercepto nulo, e 1 = valor paramétrico para o coeficiente angular sob a pressuposição de H0 ser verdadeira. Para todos os procedimentos estatísticos descritos, adotou-se valor $\mathrm{P}=0,05$. 
Os dados referentes ao intervalo entre partos e período de serviço de ovelhas com crias do sexo feminino e masculino foram submetidos à análise de variância e regressão, que utilizou como fonte de variação o efeito da idade de desmame utilizando o programa estatístico Statistical Analysis System (SAS, 2003), ao nível de 5\% de significância.

\section{RESULTADOS E DISCUSSÃO}

A relação do intervalo entre parto e período de serviço de ovelhas com crias em manejo alimentar sem suplementação e com suplementação indicou não-aceitação da hipótese de nulidade (Tab. 1), apontando, na relação analisada, a existência de um valor constante somando o tempo de intervalo entre partos e período de serviço das ovelhas.

Verificou-se vício de tempo longo do manejo alimentar das crias de $+3,7 \%(\mathrm{P}<0,05)$ para o intervalo entre partos e de $+1,4 \%(\mathrm{P}<0,05)$ para o período de serviço, que é atribuído à não suplementação das crias. O fornecimento de alimento concentrado em alimentador privativo para as crias promove melhoria para a matriz ao diminuir a quantidade e frequência de mamadas, assim são menos exigidas na lactação.

Tabela 1. Estimativas de parâmetros, níveis descritivos de probabilidade para as hipóteses de nulidade e coeficientes de determinação $\left(\mathrm{r}^{2}\right)$ para as regressões do intervalo entre partos (IP) e período de serviço (PS) de ovelhas mestiças da raça Santa Inês manejadas em Brachiaria humidícula, com crias em manejo alimentar sem suplementação e com suplementação em alimentador privativo

\begin{tabular}{|c|c|c|c|c|c|c|}
\hline \multirow{3}{*}{ Item } & \multicolumn{4}{|c|}{ Modelo Completo } & \multirow{3}{*}{$\mathrm{R}^{2}$} & \multirow{3}{*}{${ }^{3} \mathrm{VTL}$} \\
\hline & \multicolumn{2}{|c|}{ Intercepto } & \multicolumn{2}{|c|}{ Coeficiente de inclinação } & & \\
\hline & Estimativa & ${ }^{1}$ Valor-P & Estimativa & ${ }^{2}$ Valor-P & & \\
\hline IEP $^{3}$ & 15,53 & 0,0001 & 1,037 & 0,0001 & 0,859 & $+3,7 \%$ \\
\hline $\mathrm{PS}^{3}$ & 2,66 & 0,0001 & 1,014 & 0,0001 & 0,993 & $+1,4 \%$ \\
\hline
\end{tabular}

Eloy et al. (2011), em trabalho com ovelhas da raça Santa Inês, observaram que a sucção intensa da amamentação contínua em relação à amamentação controlada demonstrou ser um estímulo eficaz para a secreção de prolactina. Esses autores constataram estro mais precoce no grupo de ovelhas que apresentaram maiores níveis de progesterona no pós-parto. De acordo com Teleb et al. (2003), o nível de progesterona tende a se manter estável no pós-parto e tem uma correlação negativa com a prolactina, que age controlando o retorno à atividade ovariana.

A estimativa do coeficiente de inclinação da reta do intervalo entre parto prediz que, para um dia de intervalo de parto de ovelhas com crias em manejo alimentar com suplementação, as ovelhas com crias em manejo alimentar sem suplementação promovem em média 1,037 dias, ou seja, 0,037 dias a mais. Considerando o intervalo entre partos médio observado para o desmame entre 56 e 98 dias de idade de 255,59 dias para ovelhas com cria ao pé em manejo alimentar com suplementação, o intervalo de parto das ovelhas com cria ao pé sem suplementação seria 265 dias.

Houve efeito linear crescente $(\mathrm{P}<0,05)$ da idade de desmame sobre o intervalo entre partos (Tab. 2 e 3). Dessa forma, à medida que se prolongou a idade de desmame das crias, aumentou o intervalo entre partos, minimizando o desempenho reprodutivo das ovelhas.

Quando o desmame é realizado precocemente, a matriz se recupera mais rapidamente; pois, durante o período de lactação, as matrizes entram em balanço energético negativo, o que provoca perda de condição corporal em virtude da oxidação das reservas corporais para produção de leite. A manutenção do peso corporal das matrizes possibilita um sistema de produção mais intensivo na produção de cordeiros (Rosa et al., 2007), com a melhoria na eficiência reprodutiva das ovelhas. 
Desempenho reprodutivo...

Tabela 2. Intervalo entre partos (dias) de ovelhas mestiças da raça Santa Inês manejadas em Brachiaria humidícula, de acordo com idade de desmame e sexo das crias

\begin{tabular}{lcccccrcc} 
& \multicolumn{4}{c}{ Idade de desmame (dias) } & \multirow{2}{*}{ E } & & \multicolumn{2}{c}{ Valor P } \\
\cline { 2 - 4 } \cline { 8 - 9 } Sexo & 56 & 70 & 84 & 98 & & & Linear & Quadrático \\
\hline${ }^{2}$ Macho & 255,25 & 256,27 & 265,45 & 279,29 & 2,8845 & & 0,0001 & 0,0616 \\
${ }^{3}$ Fêmea & 250,41 & 254,74 & 255,49 & 274,38 & 2,8975 & & 0,0015 & 0,0770 \\
\hline
\end{tabular}

${ }^{1} \mathrm{EPM}=$ erro padrão da média; ${ }^{2}$ Macho, $\hat{\mathrm{Y}}=219,3575+0,5806 \mathrm{x}, \mathrm{R}^{2}=0,6618 ;{ }^{3}$ Fêmea, $\hat{\mathrm{Y}}=218,79000+0,51902 \mathrm{x}$, $\mathrm{R}^{2}=0,5240$.

A idade de desmame de 56 dias possibilitou à matriz retomar a atividade reprodutiva e conceber com antecedência, o que ocasionou intervalo entre partos médio de 252,83 dias, desempenho reprodutivo este que, entre as idades de desmame utilizadas, mais se aproxima da obtenção de três partos a cada dois anos.
Quando as crias foram alimentadas com concentrado em alimentador privativo, a idade de desmame de 56 dias possibilitou intervalo entre partos médio de 247,87 dias (Tab. 3); desempenho reprodutivo que permite a obtenção de três partos a cada dois anos.

Tabela 3. Intervalo entre partos (dias) de ovelhas mestiças da raça Santa Inês manejadas em Brachiaria humidícula, de acordo com idade de desmame e sexo das crias suplementadas com alimento concentrado em alimentador privativo

\begin{tabular}{|c|c|c|c|c|c|c|c|}
\hline \multirow[b]{2}{*}{ Sexo } & \multicolumn{4}{|c|}{ Idade de desmame (dias) } & \multirow{2}{*}{${ }^{1} \mathrm{EPM}$} & \multicolumn{2}{|c|}{ Valor P } \\
\hline & 56 & 70 & 84 & 98 & & Linear & Quadrático \\
\hline${ }^{2}$ Macho & 250,25 & 251,25 & 255,75 & 272,50 & 3,3034 & 0,0100 & 0,1469 \\
\hline${ }^{3}$ Fêmea & 245,50 & 249,75 & 250,75 & 269,00 & 3,2773 & 0,0089 & 0,1942 \\
\hline
\end{tabular}

O pico de produção de leite da ovelha ocorre entre a terceira e quarta semana após o parto, sendo que $75 \%$ da lactação é produzida nas oito primeiras semanas (Pacheco e Quirino, 2008). Nas primeiras semanas de vida, a cria depende exclusivamente do leite materno; a dependência do leite para o desenvolvimento inicial dos cordeiros é fato inquestionável. Estudos sobre o momento mais adequado do desmame deve ser realizado; pois, à medida que o cordeiro se desenvolve, a contribuição do leite diminui gradualmente e o crescimento passa a ser dependente de alimentos sólidos para o desenvolvimento de suas papilas (Coutinho e Silva, 1989; Cunha et al., 1999), uma vez que o valor nutritivo das forrageiras cultivadas e a adaptação dos animais são diferente às condições edafoclimáticas.

O intervalo entre partos está diretamente relacionado com o período de serviço, pois, quanto mais curto ele for, menor será o intervalo entre partos, aumentando, consequentemente, a produção de cordeiros por ovelha ao ano (Simplício, 2008).
Houve efeito linear crescente $(\mathrm{P}<0,05)$ da idade de desmame sobre o período de serviço (Tab. 4 e 5). Esse resultado evidencia que, à medida que é aumentada a idade de desmame das crias, eleva-se o período de serviço das matrizes, fato atribuído ao maior período em que as crias ficaram sendo amamentadas. Eloy et al. (2011), avaliando o efeito de diferentes manejos de amamentação sobre a atividade ovariana pósparto em ovelhas da raça Santa Inês, constataram que a amamentação tem influencia sobre a atividade ovariana. A continuidade da cria ao pé da mãe estimula a síntese e a secreção de prolactina, que inibe a liberação dos hormônios progestágenos e, consequentemente, inibe o crescimento e a maturação folicular e a ovulação (Souza e Simplício, 1999), diminuindo a taxa de concepção e aumentando o período de serviço.

A idade de desmame de 56 dias possibilitou um período de serviço médio das matrizes com crias sem suplementação de 98,85 dias; desempenho reprodutivo entre as idades de desmame que mais se aproxima do período de serviço necessário para a obtenção de três partos a cada dois anos. 


\section{Oliveira et al.}

Tabela 4. Período de serviço (dias) de ovelhas mestiças da raça Santa Inês manejadas em Brachiaria humidícula, de acordo com idade de desmame e sexo das crias

\begin{tabular}{|c|c|c|c|c|c|c|c|}
\hline \multirow[b]{2}{*}{ Sexo } & \multicolumn{4}{|c|}{ Idade de desmame (dias) } & \multirow[b]{2}{*}{${ }^{1} \mathrm{EPM}$} & \multicolumn{2}{|c|}{ Valor P } \\
\hline & 56 & 70 & 84 & 98 & & Linear & Quadrático \\
\hline${ }^{2}$ Macho & 101,25 & 102,26 & 106,80 & 123,71 & 2,4627 & 0,0001 & 0,0612 \\
\hline${ }^{3}$ Fêmea & 96,45 & 100,74 & 101,49 & 120,18 & 2,4805 & 0,0001 & 0,0813 \\
\hline
\end{tabular}

${ }^{1} \mathrm{EPM}=$ erro padrão da média; ${ }^{2}$ Macho, $\hat{\mathrm{Y}}=68,94500+0,51375 \mathrm{x}, \mathrm{R}^{2}=0,7108 ;{ }^{3}$ Fêmea, $\hat{\mathrm{Y}}=65,13425+0,51404 \mathrm{x}$, $\mathrm{R}^{2}=0,7014$.

Quando as crias foram alimentadas com alimento concentrado em alimentador privativo, a idade de desmame de 56 dias possibilitou à matriz melhor desempenho reprodutivo, com período de serviço médio de 97,87 dias (Tab. 5).
Desempenho reprodutivo este que permite a obtenção de 1,5 parto por ovelha/ano, considerando um período de gestação de 150 dias.

Tabela 5. Período de serviço (dias) de ovelhas mestiças da raça Santa Inês manejadas em Brachiaria humidícula, de acordo com idade de desmame e sexo de crias suplementadas com alimento concentrado em alimentador privativo

\begin{tabular}{|c|c|c|c|c|c|c|c|}
\hline \multirow[b]{2}{*}{ Sexo } & \multicolumn{4}{|c|}{ Idade de desmame (dias) } & \multirow[t]{2}{*}{${ }^{1} \mathrm{EPM}$} & \multicolumn{2}{|c|}{ Valor P } \\
\hline & 56 & 70 & 84 & 98 & & Linear & Quadrático \\
\hline${ }^{2}$ Macho & 100,25 & 101,25 & 104,75 & 122,50 & 2,5237 & 0,0002 & 0,0611 \\
\hline${ }^{3}$ Fêmea & 95,50 & 99,75 & 100,50 & 119,00 & 2,5218 & 0,0001 & 0,0804 \\
\hline
\end{tabular}

${ }^{1} \mathrm{EPM}=$ erro padrão da média; ${ }^{2}$ Macho, $\hat{\mathrm{Y}}=68,55350+0,50173 \mathrm{x}, \mathrm{R}^{2}=0,6456 ;{ }^{3}$ Fêmea, $\hat{\mathrm{Y}}=64,50000+0,50893 \mathrm{x}$, $\mathrm{R}^{2}=0,6651$.

O período de serviço médio observado para o desmame entre 56 e 98 dias foi de 106 dias, para ovelhas mestiças da raça Santa Inês em pastagem de Brachiaria humidícula. Período de serviço inferior foi constatado por Machado (1999), em pesquisa com um plantel de 25 matrizes deslanadas, alimentadas em pastagem de Braquiarão (Brachiaria brizantha $c v$. marandu), em Uberlândia-MG, que constatou período de serviço de 82 dias. É provável que o melhor valor nutricional da Brachiaria brizantha para alimentação de ovinos em relação à Brachiaria humidícula tenha possibilitado um melhor desempenho reprodutivo.

A relação do intervalo entre partos (IP) e período de serviço (PS) de ovelhas deslanadas com crias do sexo masculino e feminino indicou nãoaceitação da hipótese de nulidade (Tab. 6), apontando a existência de um valor constante somando o tempo de intervalo entre partos e o período de serviço das matrizes.

Tabela 6. Estimativas de parâmetros, níveis descritivos de probabilidade para as hipóteses de nulidade e coeficientes de determinação $\left(\mathrm{r}^{2}\right)$ para as regressões do intervalo entre partos (IP) e período de serviço (PS) de ovelhas mestiças da raça Santa Inês manejadas em Brachiaria humidícula em função do sexo das crias

\begin{tabular}{|c|c|c|c|c|c|c|}
\hline \multirow{3}{*}{ Item } & \multicolumn{4}{|c|}{ Modelo Completo } & \multirow[b]{3}{*}{$\mathrm{R}^{2}$} & \multirow[b]{3}{*}{${ }^{3} \mathrm{VTL}$} \\
\hline & \multicolumn{2}{|c|}{ Intercepto } & \multicolumn{2}{|c|}{ Coeficiente de inclinação } & & \\
\hline & Estimativa & Valor $-\mathrm{P}^{1}$ & Estimativa & Valor- $\mathrm{P}^{2}$ & & \\
\hline $\mathrm{IP}^{3}$ & 9,83 & 0,0001 & 1,020 & 0,0001 & 0,949 & $+2,0 \%$ \\
\hline $\mathrm{PS}^{3}$ & 4,45 & 0,0001 & 1,008 & 0,0001 & 0,994 & $+0,8 \%$ \\
\hline
\end{tabular}

${ }^{1} \mathrm{H} 0: \beta 0=0 ; \mathrm{Ha}: \beta 0 \neq 0 ;{ }^{2} \mathrm{H} 0: \beta 1=1 ; \mathrm{Ha}: \beta 1 \neq 1:{ }^{3}$ Vício de tempo longo $(\%)=(\beta-1) \times 100$

Verificou-se vício de tempo longo do sexo das crias, de $+2,0 \%(\mathrm{P}<0,05)$ para o intervalo entre partos de $+0,8 \%(\mathrm{P}<0,05)$ para o período de serviço das ovelhas. A diferenciação sexual no desenvolvimento embrionário e fetal ocorre em três etapas: sexo cromossômico, sexo gonadal e sexo fenotípico. No momento da fertilização é determinado o sexo cromossômico quando o oócito X é fertilizado por um espermatozóide que carrega o cromossomo $\mathrm{X}$ ou $\mathrm{Y}$ (Zenteno- 
Ruiz et al., 2001). Posteriormente, é determinado o sexo gonadal, em que o gene SRY, localizado no cromossomo Y, é responsável pela diferenciação da gônada masculina. Se o indivíduo é do sexo genético XX e não possui o gene SRY, a gônada se diferencia em ovário, sexo feminino. A disposição natural é que qualquer feto desenvolva uma genitália externa e conformação corporal feminina na ausência dos efeitos masculinizantes dos andrógenos (Howden, 2004). O sexo fenotípico se desenvolve de forma ativa no macho, estimulado pela testosterona produzida pelas gônadas diferenciadas (Nascimento e Santos, 2003). Portanto, a ação dos andrógenos durante o desenvolvimento fetal provavelmente exige da matriz um maior período para vir a preparar o sistema reprodutivo para uma nova concepção. A estimativa do coeficiente de inclinação da reta prediz que, para um dia de intervalo entre parto da matriz com cria do sexo feminino, a matriz com cria do sexo masculino tem em média 1,020 dias a mais, ou seja, considerando o intervalo de parto médio de 273 dias, o intervalo de parto do sexo masculino seria 278 dias.

A relação do ganho de peso diário de cordeiros do sexo masculino e feminino mestiços da raça Santa Inês indicou não-aceitação da hipótese de nulidade (Tab. 7), indicando a existência de um valor constante, somando o ganho de peso diário dos cordeiros do nascimento ao desmame e no pós-desmame.

Tabela 7. Estimativas de parâmetros, níveis descritivos de probabilidade para as hipóteses de nulidade e coeficientes de determinação $\left(\mathrm{r}^{2}\right)$ para as regressões do ganho de peso diário de cordeiros mestiços da raça Santa Inês do sexo masculino e feminino do nascimento ao desmame (GPND) e pós-desmame (GPPD)

\begin{tabular}{|c|c|c|c|c|c|c|}
\hline \multirow{3}{*}{ Item } & \multicolumn{4}{|c|}{ Modelo Completo } & \multirow[b]{3}{*}{$\mathrm{R}^{2}$} & \multirow[b]{3}{*}{${ }^{3} \mathrm{VTL}$} \\
\hline & \multicolumn{2}{|c|}{ Intercepto } & \multicolumn{2}{|c|}{ Coeficiente de inclinação } & & \\
\hline & Estimativa & Valor $-\mathrm{P}^{1}$ & Estimativa & Valor $-\mathrm{P}^{2}$ & & \\
\hline GPND & 40,61 & 0,0001 & 1,352 & 0,0001 & 0,645 & $+35,2 \%$ \\
\hline GPPD $^{3}$ & 28,66 & 0,0001 & 1,369 & 0,0001 & 0,316 & $+36,9 \%$ \\
\hline
\end{tabular}

${ }^{\mathrm{T}} \mathrm{H} 0: \beta 0=0 ; \mathrm{Ha}: \beta 0 \neq 0 ;{ }^{2} \mathrm{H} 0: \beta 1=1 ; \mathrm{Ha}: \beta 1 \neq 1:{ }^{3}$ Vício de tempo longo $(\%)=(\beta-1) \times 100$.

Verificou-se vício de tempo longo do sexo de + $35,2 \%(\mathrm{P}<0,05)$ para o ganho de peso diário dos cordeiros do nascimento ao desmame criados com as ovelhas progenitoras em pastagem de Brachiaria humidícula. E constatou-se também vício de tempo longo do sexo de $+36,9 \%$ $(\mathrm{P}<0,05)$ para o ganho de peso diário dos cordeiros no pós-desmame em confinamento. Em média, os ovinos machos são mais pesados e ganham mais peso do nascimento à desmama do que as fêmeas (Camacho et al., 2007). A estimativa do coeficiente de inclinação da reta prediz que, para um grama de ganho de peso de ovinos da raça Santa Inês do sexo feminino, os ovinos do sexo masculino ganham em média 1,36 gramas, ou seja, 0,36 gramas a mais do nascimento ao desmame e no pós-desmame.

\section{CONCLUSÕES}

A suplementação diária das crias em alimentador privativo e a redução da idade de desmame otimiza a eficiência reprodutiva de ovelhas deslanadas em pastagem de Brachiaria humidícula. O sexo da cria é fonte de variação na análise do desempenho reprodutivo das matrizes ovinas e no ganho de peso diário de cordeiros mestiços da raça Santa Inês do nascimento ao desmame e após o desmame.

\section{REFERÊNCIAS}

ARAÚJO FILHO, J.T.; COSTA, R.G.; FRAGA, A.B. et al. Desempenho e composição da carcaça de cordeiros deslanados terminados em confinamento com diferentes dietas. Rev. Bras. Zootec., v.39, p.363-371, 2010.

CAMACHO, A.; PÉREZ, V.; MATA, J.; BERMEJO, L.A. Análisis del potencial productivo del ovino canario de pelo. Arc. Zootec., v.56, p.507-510, 2007.

COUTINHO, G.C.; SILVA, L.H.V. Manejo reprodutivo dos ovinos: manual técnico. Florianópolis: CIDASC, 1989. 56p.

CUNHA, E.A.; SANTOS, L.E.; BUENO, M.S.; VERÍSSIMO, C.J. (Ed). Produção intensiva de ovinos. Brasil: NOVA ODESSA, 1999. 49p. 
ELOY, A.M.X.; SOUZA, P.H.F.; SIMPLICIO, A.A. Atividade ovariana pós-parto em ovelhas Santa Inês sob diferentes manejos de amamentação na região semi-árida do Nordeste. Rev. Bras. Saúde Prod. An., v.12, p.970-983, 2011.

HOWDEN, K.J. Androgen insensitivity syndrome in a Thoroughbred mare 64, XY testicular feminization. Can Vet. J., v.45, p.501503,2004

LANDIM, A.V.; CASTANHEIRA, M.; FIORAVANTI, M.C.S. et al. Physical, chemical and sensorial parameters for lambs of different groups, slaughtered at different weights. Trop. Anim. Health Prod., v.43, p.1089-1096, 2011.

MACHADO, T.M.M. Comportamento Reprodutivo de Ovinos Deslanados no Município de Uberlândia - MG. Rev. Bras. Reprod. Anim., v.23, p.189-191, 1999.

NASCIMENTO, E.F.; SANTOS, R.L. Patologia da reprodução dos animais domésticos. 2.ed. Rio de Janeiro: GUANABARA KOOGAN, 2003. 137p.

PACHECO, A.; QUIRINO, C.R. Estudo das características de crescimento em ovinos. Pubvet, v.2, p.1982-1263, 2008.

ROSA, G.T.; SIQUEIRA, E.R.; GALLO, S.B.; MORAES, S.S.S. Influência da suplementação no pré-parto e da idade de desmama sobre o desempenho de cordeiros terminados em confinamento. Rev. Bras. Zootec., v.36, p.953959, 2007.
SAS INSTITUTE. SAS system for Windows. Version 8.0. Cary: SAS Institute Inc. 2003.

SASA, A.; NONAKA, K.O.; BALIEIRO, J.C.C.; COELHO, L.A. Progesterona plasmática de ovelhas submetidas ao efeito-macho e mantidas sob diferentes condições nutricionais. Arq. Bras. Med. Vet. Zootec., v.63, p.1066-1072, 2011.

SEI-BA. Informações geoambientais. 2009. Disponível em: <http://www.sei.ba.gov.br>. Acessado em: 7 jan. 2013.

SIMPLÍCIO, A.A. Estratégias de manejo reprodutivo como ferramenta para prolongar o período de oferta de carnes caprina e ovina no Brasil. Tec. Cienc. Agrop., v.2, p.29-39, 2008.

SOUZA, P.H.F.; SIMPLÍCIO, A.A. Efeito da Amamentação sobre o Desempenho Reprodutivo Pós-Parto em Ovelhas da Raça Santa Inês. Cienc. Vet. Trop., v.2, p.115-124, 1999.

TELEB, D.F.; GABR, M.K.; GAAFAR, K.M. Manipulation of lactation and suckling on the resumption of postpartum reproductive activity in Damascus goats. Small Rumin. Res., v.49, p.183-192, 2003.

VILLAS BOAS, A.S.; ARRIGONI, M.B.; SILVEIRA, A.C. et al. Idade à desmama e manejo alimentar na produção de cordeiros superprecoces. Rev. Bras. Zootec., v.32, p.19691980, 2003.

ZENTENO-RUIZ, J.C.; KOFMAN-ALFARO, S.; MÉNDEZ, J.P. 46, XX sex reversal. Arch. Med. Res., v.32, p.559-566, 2001. 